\title{
BARREIRAS À ENTRADA NAS INDƯSTRIAS: O PAPEL DA FIRMA PIONEIRA
}

\author{
Luiz Guilherme Schymura de Oliveira*
}

\section{Resumo}

O principal objetivo da resenha é discutir, com a ajuda de modelos teóricos, os benefícios que uma firma usufrui pelo fato de ser a precursora na produção de um bem em um determinado mercado. Com este intuito, descreve-se situaçōes em que o pioneirismo de uma empresa propiciaria impedimentos à entrada de novas firmas. Portanto, barreiras à entrada, no escopo deste trabalho, são definidas como sendo o lucro auferido pela firma devido ao fato desta ser a primeira a operar no setor.

\begin{abstract}
What is a barrier to entry? This paper takes the view that a barrier to entry is a rent that is derived from incumbency. It is the additional profit that a firm can earn as a sole consequence of being established in an industry. No attempt is made to collect an exhaustive list of the determinants of entry.
\end{abstract}

\section{Introdução.}

Durante as últimas décadas, muito tem-se discutido sobre barreiras à entrada nas indústrias, a começar por sua própria definição. Bain (1956) define barreira à entrada como sendo a possibilidade de uma firma, no longo-prazo, cotar o preço do bem final acima do scu custo médio de produção sem induzir a entrada de novas empresas no mercado, ou scja, a referida firma é capaz de obter lucros sem ser molestada. De acordo com Stigler (1968), barreiras à entrada cm uma determinada indústria existem quando há vantagem de custos relativos da empresa já cstabclecida vis-à-vis as candidatas a ingressar no setor. No modo de entender de Baumol, Panzar c Willig (1982) barreiras à entrada surgem quando as firmas proponentes a entrar cm um detcrminado mercado são obrigadas a arcar com certos tipos de gastos que não são requeridos às empresas já cstabclecidas.

As definiçōes dadas por Stigler c Baumol, Panzar c Willig deixam claro que entradas podem ser excluídas $\mathrm{cm}$ algumas indústrias,

*Professor da Escola de Pós-Graduação em Economia da Fundação Getúlio Vargas

\begin{tabular}{llll}
\hline R. de Econometria & Rio de Janeiro & v. XI, no 1, p.99-129 abril 1991
\end{tabular}


mas se torna difícil entender o porquê da firma monopolista possuir vantagens nos custos de produção sobre as restantes potenciais concorrentes. Já o enfoque sugerido por Bain é uma tentativa de mensurar as barrciras à entrada, buscando atravćs da quantidade de lucros angariados pela empresa pioncira quantificar as dificuldades que uma nova companhia teria ao se instalar nesta indústria. Bain destaca, informalmente, três principais motivos que levariam uma companhia a monopolizar a produção: (i) cconomias de escala - existem retornos crescentes de escala na produção; (ii) diferenciação de produtos caso em que a firma, por exemplo, possui uma patente para a comercialização da mercadoria; (iii) assimetria de custos - caso cm que, por excmplo, existc "learning by doing" na produção do bem final, isto ć, a firma com experiência na produção c comercialização de um bem tem um custo menor do que uma empresa nova neste mercado.

Bain ainda sugere três tipos de comportamento para a firma pioncira em face da ameaça da entrada de novas companhias na indústria: (i) bloqueio à entrada - a firma já cstabelecida comportase como se não houvesse ameaça de entrada; c mesmo assim, não existe incentivo para novos empresários engajarem-sc no mercado; (ii) impedindo à entrada - a única companhia atuante no mercado altera scu padrão de comportamento no intuito de inibir uma possível entrada; (iii) acomodação à entrada - a companhia pioncira permite o ingresso de novas firmas no mercado por ser mais lucrativo do que criar barrciras à entrada.

O principal objetivo desta resenha é discutir, com a ajuda de modelos teóricos, os benefícios que uma firma usufrui pelo fato de ser a precursora na produção de um bem em um determinado mercado. Com este intuito, descreve-se situaçōes em que o pioncirismo de uma empresa propiciaria impedimentos à entrada de novas companhias. Desta feita, barreiras à entrada, no escopo destc trabalho, são definidas como sendo o lucro auferido pela firma devido ao fato desta ser a primeira a operar no setor.

O motivo para claborar esta recensão surgiu da tentativa de responder a seguinte questão: Como explicar que cm muitos segmentos da economia - onde a tecnologia é de conbecimento comum e de livre acesso - empresas vendam scu produto final por um preço acima do custo marginal de produção? De acordo com a tcoria microeconômica clássica, esta indagação não procederia tendo $\mathrm{cm}$ vista que, por arbi- 
tragem, o lucro tenderia a zero.

Um dos primciros a cstudar com maior profundidade csta questão foi Sylos-Labini, em scu livro "Oligopoly and Technical Progress".

Sylos observou que muitas empresas monopolistas cotavam o preço do seu bem final abaixo do preço de monopólio. Segundo seu entender, esta estratégia, à qual se deu o nome de política de preçoslimite, cra uma tentativa da firma já cstabclecida inibir futuras entradas. Embora, a justificativa, dada por Sylos, para a existência deste estratagema fosse um pouco confusa, a percepção do clo entre prática de preços abaixo dos de monopólio c barreiras à entrada foi uma das grandes contribuições para o estudo da organização das indústrias.

Com a introdução da tcoria de expectativas racionais c do instrumental de teoria dos jogos no campo da cconomia industrial, as barreiras à entrada puderam ser explicadas de mancira mais convincentc, como nos trabalhos desenvolvidos por Dixit (1979) c (1980), Bullow, Geanakoplos c Klemperer (1985b), entre outros. Boas rescnhas sobre o assunto são encontradas cm Tirole (1989), Gilbert (1989) c Shapiro (1989).

Todos os modelos aqui apresentados são de expectativas racionais. O que permite afirmar que os equilíbrios da economia são de Nash $^{1}$.

A seção 2 do presente artigo apresenta uma versão modificada do modelo de Dixit (1979). A cconomia dura por dois períodos. No 1 o período, a firma pioncira decide quanto produzir, enquanto que no período final, uma segunda cmpresa se candidata a ingressar na indústria $\mathrm{c}$ decide, com basc na obscrvação da produção estipulada pcla companhia já cstabclecida, quanto fabricar da mercadoria. Detcrmina-sc o cquilíbrio de Nash do mercado que, no caso, ć o equilíbrio de Stackelberg ${ }^{2}$, onde a empresa precursora na indústria ć a líder, c a potencial entrante a seguidora. Verifica-sc, com basc nos custos fixos de produção, a existência de cquilíbrios com: bloqucio, impedimento $\mathrm{c}$ acomodação à entrada.

\footnotetext{
${ }^{1}$ A estratégia ótima para o agente 1 é $a_{1}$ dado que a estratégia do agente 2 é $a_{2}$. Da mesma forma, a estratégia ótima para o agente 2 é $a_{2}$ dado que a estratégia do agente 1 é $a_{1}$. O par de estratégias $\left(a_{1}, a_{2}\right)$ define-se como equilíbrio de expectativas racionais ou de Nash.

${ }^{2} \mathrm{O}$ agente 1 escolhe a estratégia ótima $a_{1}$ tomando como dada a estratégia de reação do agente $2, a_{2}$. A este particular equilibrio de Nash dá-se o nome de equilibrio de Stackelberg. O agente 1 chama-se lider e o agente 2 seguidor.
} 
Dc acordo com o disposto na referida sç̧ão 2, o empresário pionciro compromete-se, no período inicial, a fabricar uma determinada quantidade do bem. Na seção 3 , questiona-se a validade desta hipótese, tendo $\mathrm{cm}$ vista que a quantidade cfetivamente fabricada pela companhia estabclecida pode não ser a mesma com a qual antes sc comprometera. O que equivale a dizer, utilizando a nomenclatura de Selten (1975), que o equilíbrio do modelo de Dixit (1979) não ć perfeito cm subjogos.

A descrição de uma versão do modelo de Dixit (1980) é o assunto da seção 4. Para scu melhor entedimento, faz-se necessário apresentar nesta introdução o conceito de custo enterrado (do inglês "sunk cost"). Custos enterrados são gastos realizados por uma firma que não podem ser climinados, mesmo que cesse a produção. Por excmplo, uma empresa compra uma máquina que não tem valor de revenda, ou ainda, uma firma adquire um terreno c constrói um campo de futcbol, onde o montante cmpatado para a constituição do campo, no caso de venda do terreno, é irrecuperável. Nas duas situaçōes acima descritas, tanto a máquina como o campo de futcbol representam custos enterrados para as companhias. Por esta definição, os custos fixos são enterrados no curto-prazo. Para um tratamento formal deste conceito ver Baumol, Panzar c Willig (1982, pgs.280 c 281).

Dixit (1980) considera uma economia que dura por dois períodos. No período inicial, a pioncira determina quanto gastar $\mathrm{cm}$ instalaçōes (scm valor de revenda). O custo enterrado $\mathrm{em}$ capacidade instalada proporciona uma queda no custo marginal de fabricação da mercadoria. No $2^{\circ}$ período, a companhia potencial entrante, com base nos custos enterrados da pioncira, decide quanto produzir. Determinase assim, o equilíbrio de Cournot- $\mathrm{Nash}^{3}$ do modelo como função dos custos fixos de produção.

Em Dixit (1980), as instalaçōes ociosas representam puro desperdício de dinheiro. Na seçõ 5, descreve-se o modelo de Bullow, Geankoplos c Klemperer (1985) que garante à capacidade subutilizada uma importância estratégica.

\footnotetext{
3 A quantidade ótima produzida pela companhia 1 é $q_{1}$ dado que a firma 2 produz $q_{2}$ e a quantidade ótima produzida pela firma 2 é $q_{2}$ dado que a companhia 1 produz $q_{1}$. Ao equilíbrio de Nash em quantidades, $\left(q_{1}, q_{2}\right)$, dá-se o nome de equilibrio de Cournot.
} 
Na seção 6, define-se o que scjam bens substitutos estratégicos e complementares estratégicos. Estes conceitos possibilitam um melhor entedimento do valor da capacidade ociosa para as firmas.

Finalmentc, na seção 7 conclui-se o trabalho.

\section{O modelo de duopólio e o líder de Stackelberg.}

Durante os anos $60 \mathrm{c}$ o início dos 70, acreditava-se que uma cmpresa monopolista, na tentativa de dissuadir novas firmas de entrarem na indústria, cotava o preço de scu bem final abaixo do que seria o "verdadciro " preço de monopólio. Bain (1956), Modigliani (1958) c Sylos-Labini (1962) foram os idealizadores desta teoria, à qual sc deu o nome de política de preços-limite. Entretanto, esta argumentação não conseguia responder a muitas questōes, entre clas: (i) sendo a tecnologia de livre acesso e de conhecimento comum, por que uma potencial entrante scria influenciada pela estratégia da pioncira? (ii) qual a vantagem que a empresa estabclecida tiraria da política de preços-limite?

Um dos primciros trabalhos teóricos a dar respaldo técnico à visão intuitiva de Bain, Sylos c Modigliani foi o de Dixit (1979).

Nesta seção, apresenta-sc uma versão do modelo de Dixit (1979). O ferramental por cle utilizado ć oriundo do trabalho de Stackelberg (1934).

Dixit considera uma indústria composta por duas firmas, a primeira já estabclecida c a segunda candidata a instalar-se. A cconomia funciona durante dois períodos. No período inicial, a pioncira determina a quantidade que produzirá no segundo período, sabendo que a candidata ao ingresso tomará sua decisão de produção com base neste saber. No período final, a potencial entrante decide, com base na informação da oferta da primcira firma, sc ingressa ou não na indústria, e em caso afirmativo, com que produção. Este tipo de equilíbrio é conhecido como de Stackelberg, onde a primeira companhia age como líder e a segunda firma desempenha o papel de seguidora.

Imaginc que a função demanda pela mercadoria scja dada por:

$$
P(Q)=6-Q \text { e } Q=q_{1}+q_{2}
$$

onde, $Q, \boldsymbol{q}_{1}$ c $q_{2}$ representam, respectivamente, a produção total da indústria, da empresa $1 \mathrm{e}$ da proponente a entrar, enquanto $P$ é o preço do bem final. 
A função custo total de produção ć a mesma para as duas firmas, c pode ser representada por:

$$
C_{i}\left(q_{i}\right)=f+3 q_{i}, \quad i=1,2
$$

onde, $f$ ć o custo fixo.

Isto posto, as funçōes lucro $\left(\pi_{i}, \quad i=1,2\right)$ das duas firmas aprescntam-sc como:

$$
\pi_{i}\left(q_{1}, q_{2}\right)=\left[3-q_{1}-q_{2}\right] q_{i}-f, \quad i=1,2
$$

Para um melhor entendimento do problema, deve-sc construir as funçōcs de reação das duas firmas.

Da hipótcse de maximização de lucro das duas cmpresas tem-sc

$$
\max _{q_{i}}\left[3-q_{1}-q_{2}\right] q_{i}-f, \quad i=1,2
$$

Assim, com as condiçōes de $1^{\underline{a}}$ ordem c o fato das firmas só produzircm quando o retorno é positivo, vem:

$$
R_{i}\left(q_{j}\right)=q_{i}=\left\{\begin{array}{c}
\frac{3-q_{j}}{2}, \text { sc } q_{j}<3-2 \sqrt{f} \\
0, \quad \text { sc } q_{j} \geq 3-2 \sqrt{f},
\end{array}\right.
$$

$i, j=1,2$ c $i \neq j$

ondc, $R_{i}\left(q_{j}\right)$ representa a rcação da firma $i-$ cm termos de quantidadc produzida - ao montantc fabricado pcla cmpresa $j$. O gráfico 2.1 ilustra o problema.

Os equilíbrios de Cournot-Nash, $q_{1}^{c}, q_{2}^{c}$ destc mercado são dados pcla interseção das curvas de rcação $R_{1}\left(q_{2}\right)$ c $R_{2}\left(q_{1}\right)$, isto ć

$$
\left(q_{1}, q_{2}\right)=\left\{\begin{array}{crr}
(1,1), & \text { sc } 0 \leq f \leq 1 \\
\left(\frac{3}{2}, 0\right) \text { e }\left(0, \frac{3}{2}\right), & \text { sc } 1<f \leq \frac{9}{4} \\
(0,0), & \text { se } \quad f>\frac{9}{4}
\end{array}\right.
$$

\footnotetext{
${ }^{4} \hat{A}$ decisão de produção da firma $i$ como resposta à quantidade fabricada pela empresa $j$ dárse o nome de função de reação da companhia $i$.
} 


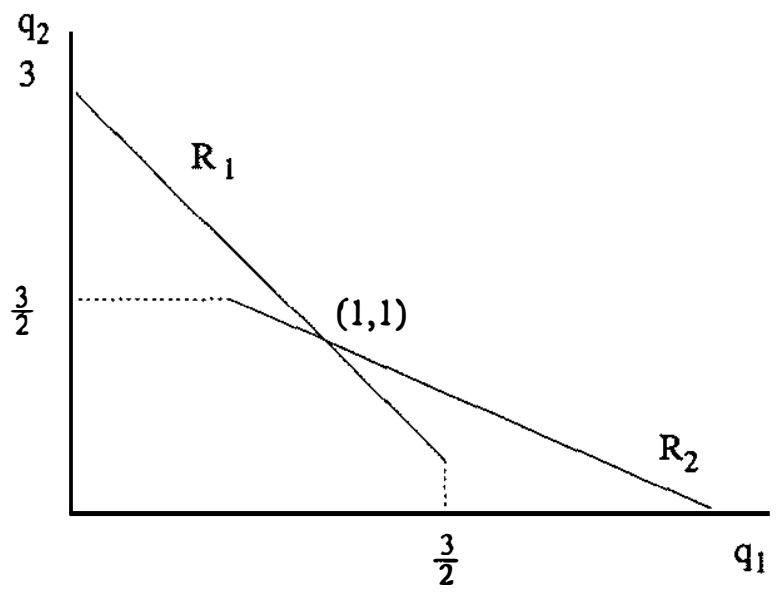

Gráfico 2.1.

Curvas de reação

Graf. 2.1.a $(f \in[0,1])$

que sc verifica quando as duas firmas entram na indústria conjuntamentc c disputam o mercado de forma não coopcrativa ${ }^{5}$.

No entanto, de acordo com Dixit, o pioncirismo dá à firma 10 dircito do primciro movimento no jogo de detcrminação das quantidades produzidas, isto ć, abandona-sc o cquilíbrio de Cournot $\mathrm{e}$ trabalha-sc com o de Stackelberg, onde a cmpresa 1 ć a líder.

Dependendo do valor de $\int$ pode-sc atingir os três tipos de equilíbrio definidos por Bain: bloqucio, impcdimento c acomodação à cntrada. Abaixo relacionam-sc as realizaçōes de $f$ c o comportamento das empresas cstabclccidas.

Proposição 2.1: A acomodação à entrada ocorrc para $f \in\left[0, \frac{9}{64}[2-\right.$ $\left.\sqrt{2}]^{2}\right)$, c o cquilíbrio de Stackclberg ć dado por $\left(q_{1}^{s a}, q_{2}^{s a}\right)=\left(\frac{3}{2}, \frac{3}{4}\right)$.

${ }^{5} \mathrm{O}$ equilibrio de Cournot é solução para jogos não-coopcrativos. Se as firmas procuram jogar cooperativamente surgem os cartéis que geram outras formas de equilíbrio, que não estão no escopo de estudos de barreiras à entrada. 


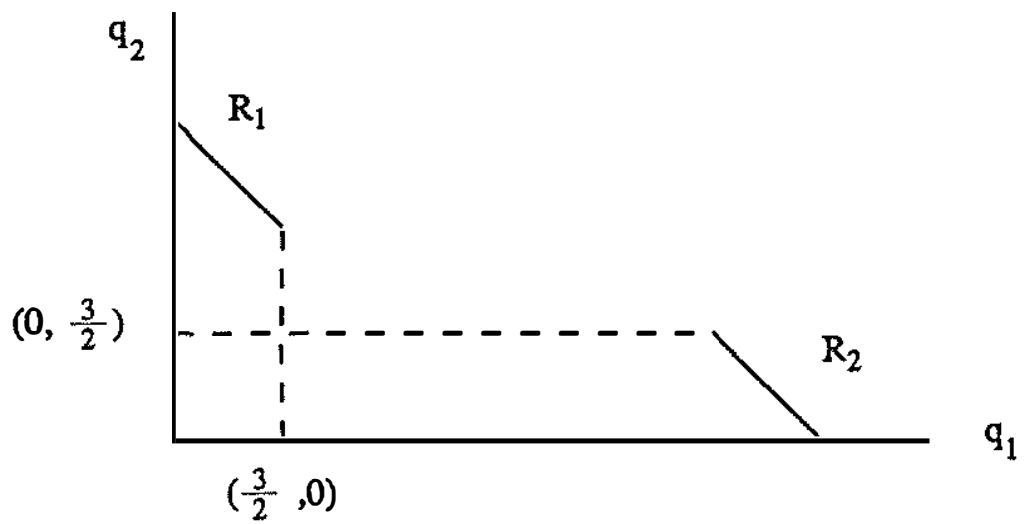

Cráfico 2.1.b.

$$
\left(f \in\left(1, \frac{9}{4}\right]\right)
$$

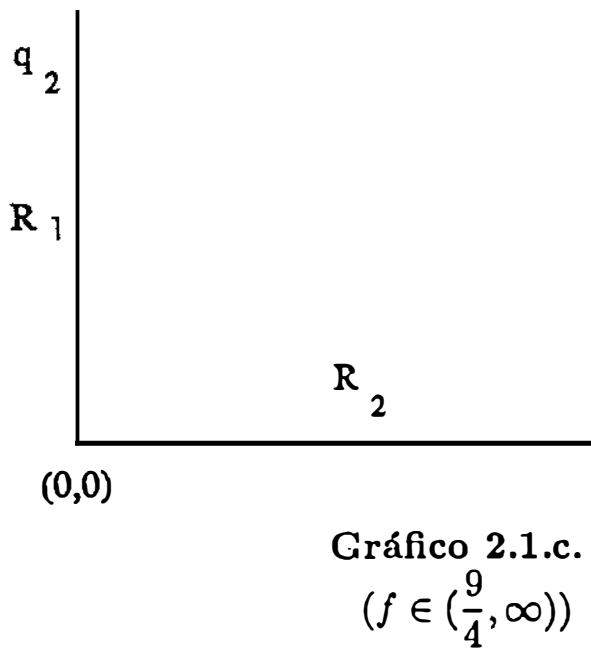




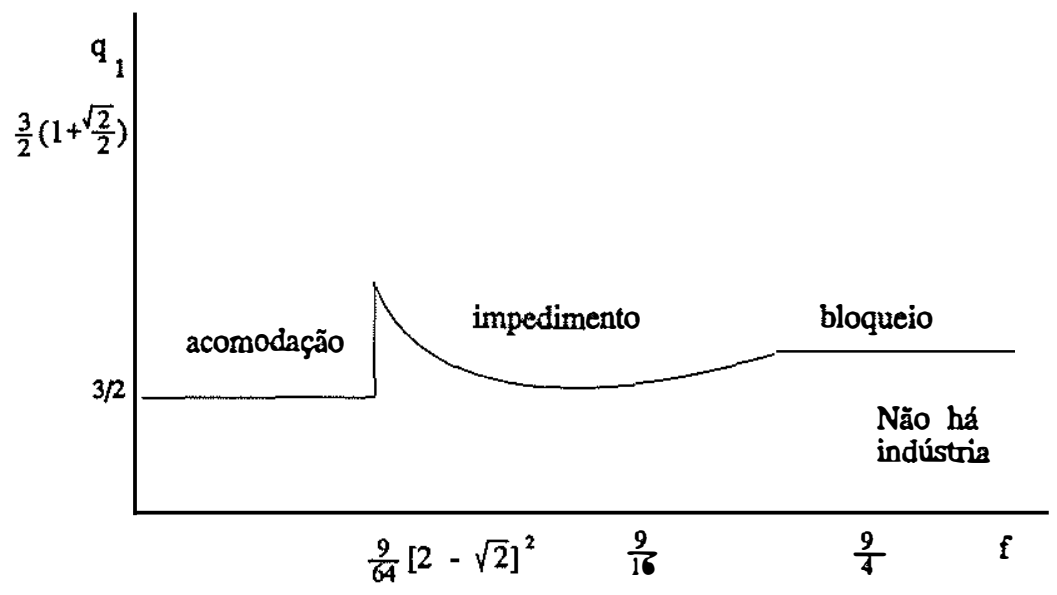

Gráfico 2.2.

Prova: (Vide Apêndicc)

Proposiçāo 2.2: O bloqucio à cntrada sc verifica quando $f \in$ $\left(\frac{9}{16}, \frac{9}{4}\right]$, o cquilíbrio de Stackclberg associado ć $\left(q_{1}^{s b}, q_{2}^{s b}\right)=\left(\frac{3}{2}, 0\right)$.

Prova: (Vidc Apêndicc)

Proposiçāo 2.3: $O$ impedimento à entrada acontece para $f \in$ $\left[\frac{9}{64}[2-\sqrt{2}]^{2}, \frac{9}{16}\right]$, com o cquilíbrio de Stackclberg assumindo o valor $\left(q_{1}, q_{2}\right)=(3-2 \sqrt{f}, 0)$.

Prova: (Vide Apêndicc)

A Tabcla 1 sumariza os resultados encontrados

O gráfico 2.2 dá uma idéia do comportamento da firma precursora com relação ao custo fixo de produção.

Como sc vê, a cxistência de equilíbrio com impedimento à entrada confirma a intuição de Bain, Sylos e Modigliani. 


\section{Tabela 1.}

\begin{tabular}{ccc} 
& $\left(q_{1}, q_{2}\right)$ & Intervalo de $f$ \\
\hline $\begin{array}{c}\text { Acomodação à } \\
\text { entrada }\end{array}$ & $\left(\frac{3}{2}, \frac{3}{4}\right)$ & {$\left[0, \frac{9}{64}[2-\sqrt{2}]^{2}\right)$} \\
\hline $\begin{array}{c}\text { Impcdimento à } \\
\text { entrada }\end{array}$ & $(3-2 \sqrt{f}, 0)$ & {$\left[\frac{9}{64}[2-\sqrt{2}]^{2}, \frac{9}{16}\right]$} \\
\hline $\begin{array}{c}\text { Bloqueio à } \\
\text { entrada }\end{array}$ & $\left(\frac{3}{2}, 0\right)$ & $\left(\frac{9}{16}, \frac{9}{4}\right]$ \\
\hline $\begin{array}{c}\text { Não existe } \\
\text { indústria }\end{array}$ & $(0,0)$ & $\left(\frac{9}{4}, \infty\right)$ \\
\hline
\end{tabular}

\section{O comportamento não crível.}

$\mathrm{Na}$ sç̧ão precedentc, discutiu-sc situaçōes de bloqucio, impedimento $\mathrm{e}$ acomodação à cntrada quando existc um jogador com dircito ao primciro movimento, no caso a firma pioncira. Entrctanto, não sc lcvantou qualquer dúvida quanto à possibilidade da cmpresa precursora não cumprir a meta de produção cstipulada no pcríodo inicial para o pcríodo derradciro. Desta fcita, o objctivo desta sç̧ão ć o de discutir a confiabilidade do comprometimento de produção por partc da pioncira.

Com cstc intuito, cm analogia ao modclo da scção 2, considerc o caso cm que $\int=0$. A função lucro das duas firmas ć tomada como

$$
\begin{aligned}
& \pi_{1}=\left(3-q_{1}-q_{2}\right) q_{1} \\
& \pi_{2}=\left(3-q_{1}-q_{2}\right) q_{2}
\end{aligned}
$$

Como visto, na scção antcrior, o cquilíbrio ocorrcria $\mathrm{cm}\left(q_{1}^{a a}\right.$, $\left.q_{2}^{s a}\right)=\left(\frac{3}{2}, \frac{3}{4}\right)$, com retornos $\left(\pi_{1}, \pi_{2}\right)=\left(\frac{9}{8}, \frac{9}{16}\right)$.

Contudo, sc a cmpresa 2 cntra no mercado ofertando sua quantidade de cquilíbrio, $q_{2}=\frac{3}{4}$, a firma 1 poderia dispor de pelo menos duas altcrnativas: 
(i) produzir a quantidade que se comprometera antes da entrada, $q_{1}=\frac{3}{2}$, que proporcionaria ganhos de $\left(\pi_{1}, \pi_{2}\right)=\left(\frac{9}{8}, \frac{9}{16}\right)$ ou, esquecer o que havia cstipulado $\left(q_{1}^{s a}=\frac{3}{2}\right)$ c produzir a quantidade que scria a melhor resposta à $q_{2}=\frac{3}{4}$, isto ć, determinar $q_{1}$ do problema de maximização.

$$
\max _{q_{1}}\left(3-\frac{3}{4}-q_{1}\right) q_{1}
$$

$\Rightarrow q_{1}=\frac{9}{8}$, que acarretaria lucros $\left(\pi_{1}, \pi_{2}\right)=\left(\frac{81}{64}, \frac{27}{32}\right)$. Claramente, neste contexto, a decisão (ii) gera um lucro maior para a empresa pioncira. O que assegura que a estratégia de compromentimento da firma já cstabclecida não ć crívcl.

Na linguagem de Selten (1975), o equilíbrio $\left(q_{1}^{s a}, q_{2}^{s a}\right)=\left(\frac{3}{4}, \frac{3}{4}\right)$, não é um "equilíbrio perfeito em subjogos" do jogo scquencial. Em outras palavras, este equilíbrio não ć robusto para o experimento no qual a firma testa o mercado para entrar. Assim, o conccito de perfeição climina amcaças que não são crívcis.

Como se vê, o equilíbrio de Stackelberg não é perfeito $\mathrm{cm}$ subjogos, e por conseguinte, não representa o ponto apropriado de produção das empresas. Dessa forma, o equilíbrio do mercado de Dixit (1979) deve ser o de quantidades de Cournot, no qual nenhuma das empresas goza do privilégio do 1 o movimento. A equação (2.1) mostra os equilíbrios de Cournot.

$$
\left(q_{1}^{c}, q_{2}^{c}\right)=\left\{\begin{array}{crr}
(1,1), & \text { sc } 0 \leq f \leq 1 \\
\left(\frac{3}{2}, 0\right) \text { c }\left(0, \frac{3}{2}\right), & \text { se } 1<\int<\frac{9}{4} \\
(0,0), & \text { sc } \quad \int>\frac{9}{4}
\end{array}\right.
$$

Como se pode obscrvar, neste equilíbrio o pioncirismo não possui nenhuma vantagem. O que permite afirmar que o fato da companhia 1 ter sido escolhida, exogenamente, para ser a 1a jogadora é fator determinante para que exista equilíbrio com impedimento à entrada. 


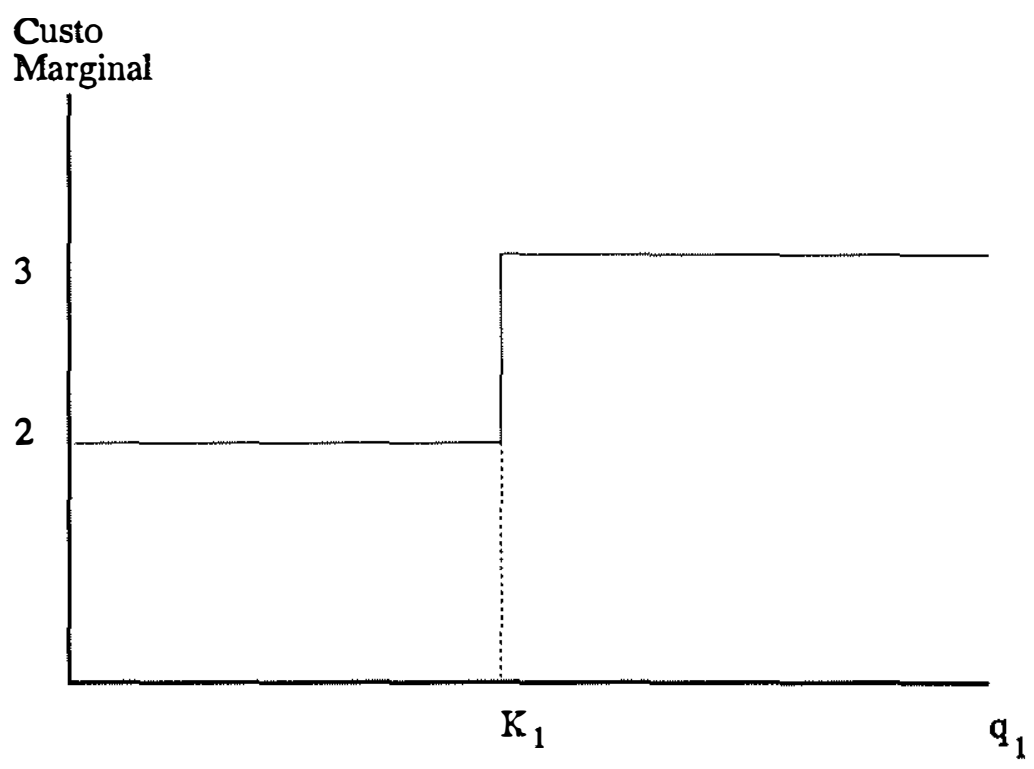

Gráfico 4.1.

4. A capacidade instalada e a barreira à entrada.

Os modelos desenvolvidos até aqui, não conseguem responder a duas importantes indagaçōes: Porque a competição se realiza em quantidades $\mathrm{c}$ não $\mathrm{cm}$ preços? O que levaria uma firma a fabricar a quantidade de produto por cla comprometida? Dixit mostra, em scu artigo de 1980, que a rsposta a cstas questōes cstá associada ao nível de capacidade instalada na indústria. Assim, as firmas teriam uma limitação na quantidade a produzir - o que justificaria o equilíbrio em quantidades (Cournot) c descartaria o equilíbrio em preços (Bcrtrand) - c, o comprometimento na quantidade a ser fabricada gozaria de confiabilidade pelo fato do custo de construção das instalaçōes ser enterrado.

O modelo de Dixit (1980) pressupõe a presença de duas firmas cm uma indústria, a já estabclecida (firma 1) c a interessada em estabelecer-sc (firma 2). As duas empresas são idênticas, exceto pclo 
pelo fato da firma 1 ter opção de decidir, antes do possível engajamento da companhia 2 ao setor, o quanto de capital empatar em capacidade instalada. Assim, a função custo da companhia 1 ć representada por

$$
C_{1}\left(q_{1}\right)=\left\{\begin{array}{r}
f+K_{1}+2 q_{1}, \text { se } q_{1} \leq K_{1} \\
f+3 q_{1}, \text { se } q_{1}>K_{1}
\end{array}\right.
$$

onde, $K_{1}$ é quantidade de capacidade instalada. Portanto, o 1 으 empresário arca com um custo marginal de 2 caso haja capacidade ociosa, c o custo marginal se cleva para 3 quando as instalaçōes não são suficientes para abrigar toda a produção (ver gráfico 4.1). Sob esta linha de raciocínio, se o investimento na instalação da capacidade produtiva fosse perfeitamente reversível, então a estrutura de custos seria simplesmente $C_{1}\left(q_{1}\right)=f+3 q_{1}$, mas como o custo de $K_{1}$ ć, por hipótese, enterrado, portanto irreversível, tem-sc a função de custos como descrita $\mathrm{cm}$ (4.1).

Como a companhia 2 ainda não possui instalaçōes, também não tem custos enterrados, a função custo de produção ć dada por,

$$
C_{2}\left(q_{2}\right)=f+3 q_{2}
$$

Considere que que a curva de demanda é dada por

$$
P(Q)=6-Q, \quad \text { onde } \quad Q=q_{1}+q_{2}
$$

Por conseguinte, tem-se a função lucro das duas empresas,

$$
\pi_{1}\left(q_{1}, q_{2}\right)=\left\{\begin{array}{l}
\left(6-q_{1}-q_{2}\right) q_{1}-f-K_{1}-2 q_{1}, \text { se } q_{1} \leq K_{1} \\
\left(6-q_{1}-q_{2}\right) q_{1}-f-3 q_{1}, \quad \text { caso contrário }
\end{array}\right.
$$

c $\pi_{2}\left(q_{1}, q_{2}\right)=\left(6-q_{1}-q_{2}\right) q_{2}-f-3 q_{2}$

\subsection{O custo fixo de produção é nulo.}

Por u m pro'slema didático, primeiramente, analisa-se o caso em que $f$ é zero.

Assim sendo, para a determinação das funçōes de reação, necessita-se das maximizaçōes de lucro de cada um dos agentes.

Para a firma 1, vem: 


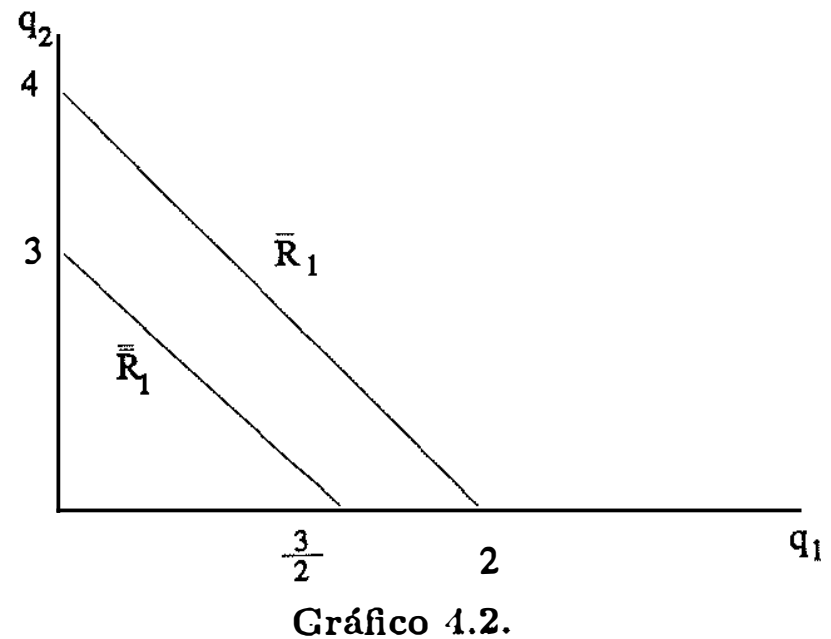

(i) Caso cm que existe capacidade ociosa

$$
\begin{aligned}
& \max _{q_{1}}\left(4-q_{1}-q_{2}\right) q_{1}-K_{1} \\
& \Rightarrow \bar{R}_{1}\left(q_{2}\right)=\frac{4-q_{2}}{2}, \text { para } q_{1} \leq K_{1}
\end{aligned}
$$

(ii) Caso cm que as instalaçōes são amplamente utilizadas

$$
\begin{aligned}
& \max _{q_{1}}\left(3-q_{1}-q_{2}\right) q_{1} \\
& \Rightarrow \bar{R}_{1}\left(q_{2}\right)=\frac{3-q_{2}}{2}, \quad \text { para } q_{1}>K_{1}
\end{aligned}
$$

que podem ser melhor visualizados no gráfico 4.2 Associada à cmpresa 2 obtćm-sc,

$$
\begin{aligned}
& \max \left(3-q_{1}-q_{2}\right) q_{2} \\
& \Rightarrow \overline{\overline{\mathrm{R}}}_{2}\left(q_{1}\right)=\frac{3-q_{1}}{2}
\end{aligned}
$$




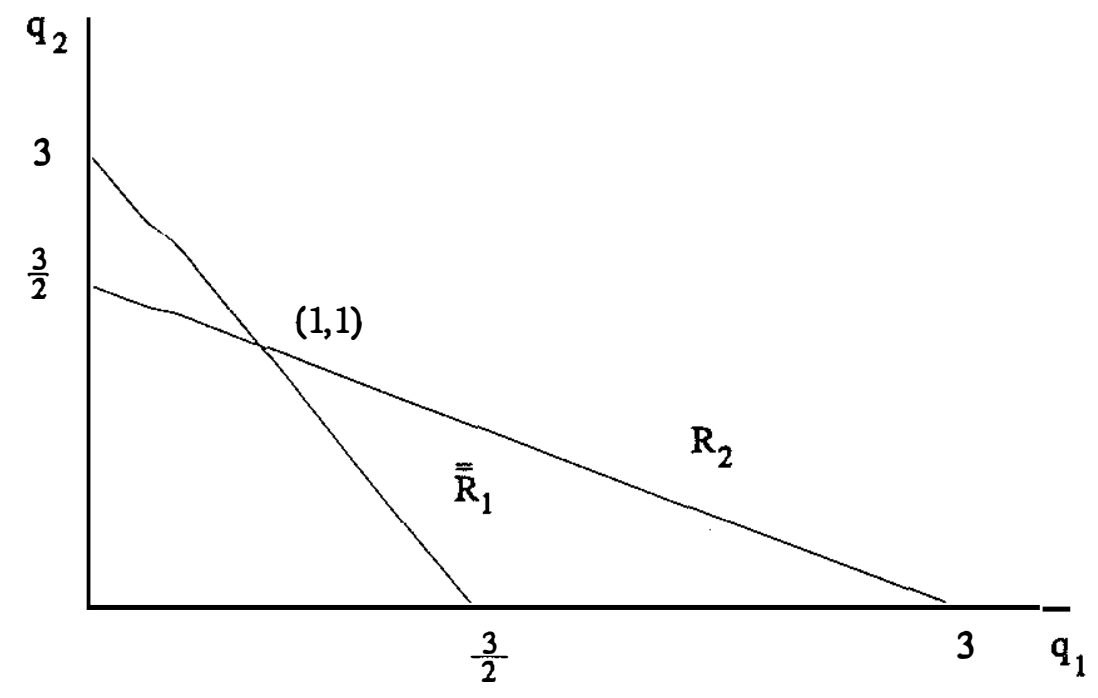

Gráfico 4.3.a.

Como se vê, a função de reação da firma 1 depende de sua escolha do nível de capacidade instalada, $K_{1}$. Dessa forma, para um dado $K_{1}$, tem-se um equilíbrio de Cournot de duopólio na interseção das duas curvas de reação. Assim, a firma estabclecida procura um nível de capacidade instalada que coloque $\mathrm{cm}$ uma melhor posição antc a concorrência. limite.

Os gráficos 4.3.a c b ilustram situaçōes de capacidade instalada

No gráfico 4.3.a, o :10 empresário não possui instalaçōes antes da cntrad a da firma 2. A indústria ć análoga à descrita na seção 2, com a diferença que na presente seção nenhuma das empresas goza do privilégio de ser a primeira a "jogar." As quantidades produzidas em equilíbrio ( de Cournot) são $\left(q_{1}, q_{2}\right)=(1,1)$.

$\mathrm{O}$ grăfico 4.3.b apresenta o caso $\mathrm{em}$ que $K_{1}$ ć igual a $\frac{5}{3}$, onde 


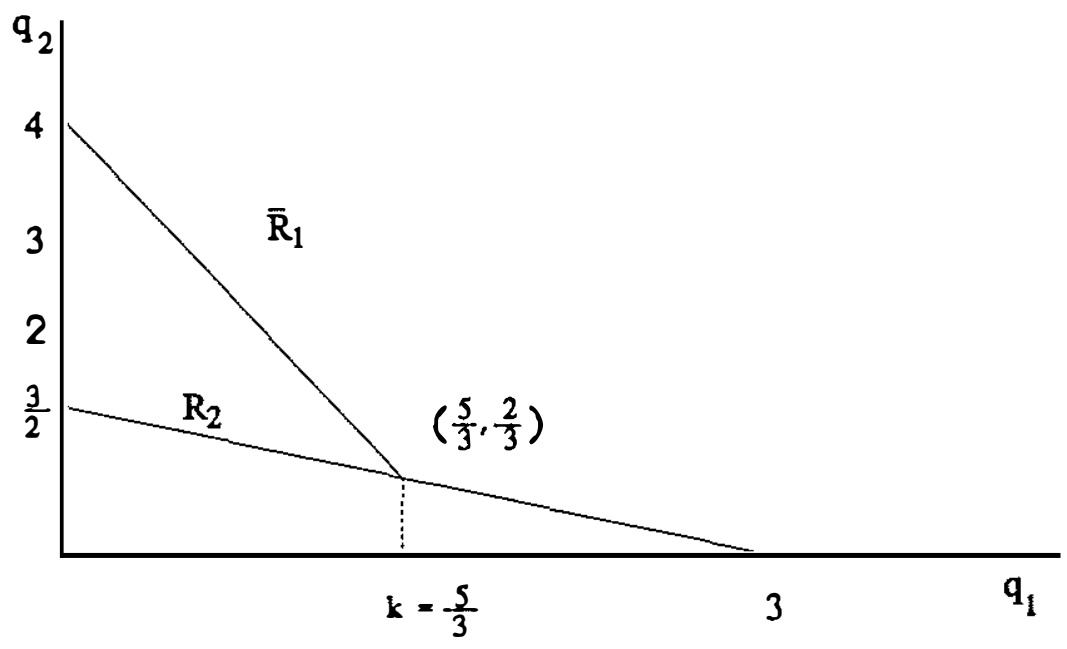

Gráfico 4.3.b.

o equilíbrio ocorre $\mathrm{cm}\left(q_{1}, q_{2}\right)=\left(\frac{5}{3}, \frac{2}{3}\right)$. Para capacidade instalada acima de $\frac{5}{3}$ o equilíbrio de mercado ć $\left(q_{1}, q_{2}\right)=\left(\frac{5}{3}, \frac{2}{3}\right)$, significando que o valor de $K_{1}$ que exceder $\frac{5}{3}$ fica ocioso c não tem qualquer valor estratégico na determinação do equilíbrio de quantidades. Assim sendo, níveis de $K_{1}$ acima de $\frac{5}{3}$ não são ameaças crívcis de retenção à entrada. O que contraria a argumentação de Spence (1977), que afirma que a capacidade ociosa tem um importante valor estratégico como determinante das quantidades de equilíbrio.

Por conseguinte, para cada valor de $K_{1} \in\left[1, \frac{5}{3}\right]$ tem-sc como interseção das curvas de reação um ponto do segmento de reta $q_{2}=\frac{3-q_{1}}{2}$ para $q_{1} \in\left[1, \frac{5}{3}\right]$ (ver gráfico 4.4). Assim, o equilíbrio de Cournot da indústria dependerá do investimento em instalaçōes por parte da pioneira. Como o 1o empresário maximiza seu retorno, o valor de $K_{1}$ ć determinado de forma a que a firma 1 estcja numa 


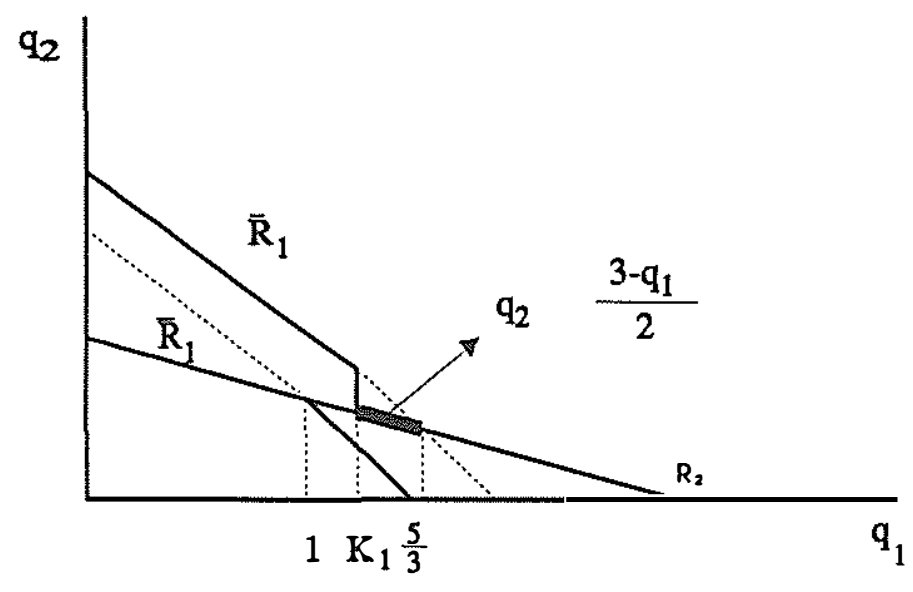

Gráfico 4.4.

curva de maior iso-lucro, o gráfico 4.5 ilustra o problema. Como sc pode observar, o ponto de lucro máximo é o equilíbrio de Stackelberg, com a pioncira como líder. O equilíbrio de Stakelberg deste mercado ć o mesmo do encontrado no modelo da seção $2,{ }^{6}\left(q_{1}, q_{2}\right)=\left(\frac{3}{4}, \frac{3}{4}\right)$.

\subsection{O custo fixo de produção é positivo.}

Até aqui, discutiu-sc o equilíbrio no caso em que duas firmas operariam no mercado. A partir deste ponto, considera-se a possibilidade da entrante não ingressar na indústria, isto ć, o lucro da potencial concorrente pode ser negativo caso decida atuar no mercado.

Proposiçāo 4.1: Os equilíbrios em quantidades de Cournot são dados pclo quadro abaixo.

${ }^{6}$ Observe que neste caso - contrariando o do ocorrido no modelo da seção 2 - 0 comprometimento em produzir uma quantidade $q_{1}$ é crivel, já que a capacidade instalada representa um investimento irreversível. 


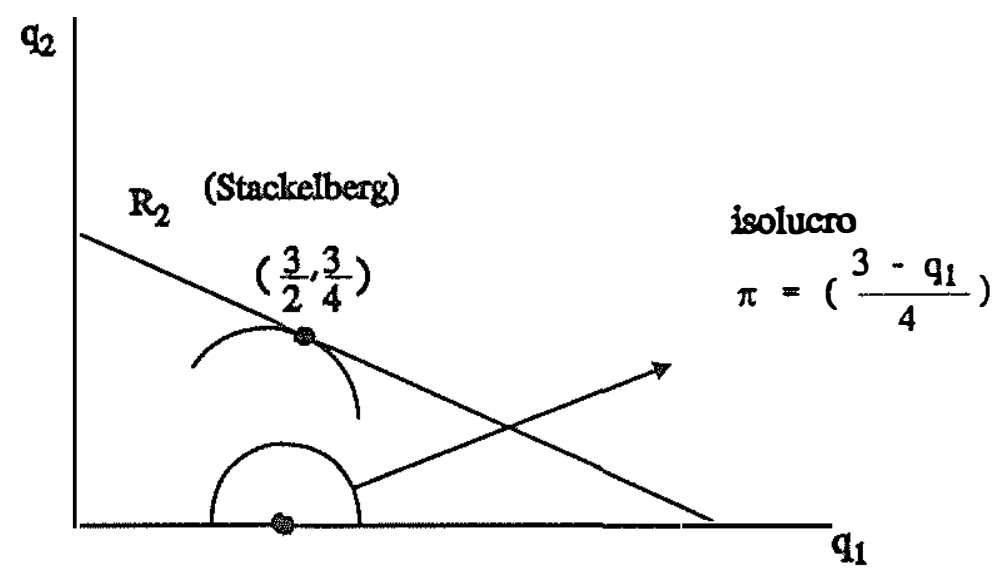

Gráfico 4.5.

Tabela 2.

\begin{tabular}{ccc} 
& $\left(q_{1}\right.$, & Intervalo de $f$ \\
\hline $\begin{array}{c}\text { Acomodação à } \\
\text { entrada }\end{array}$ & $\left(\frac{3}{2}, \frac{3}{4}\right)$ & {$\left[0, \frac{4}{9}\right)$} \\
\hline $\begin{array}{c}\text { Impedimento à } \\
\text { entrada }\end{array}$ & $(3-2 \sqrt{f}, 0)$ & {$\left[\frac{4}{9}, \frac{9}{16}\right]$} \\
\hline $\begin{array}{c}\text { Bloqueio à } \\
\text { entrada }\end{array}$ & $\left(\frac{3}{2}, 0\right)$ & $\left(\frac{9}{16}, 1\right)$ \\
\hline $\begin{array}{c}\text { Sem vantagens } \\
\text { para o pioneirismo }\end{array}$ & $\left(\frac{3}{2}, 0\right)$ ou $\left(0, \frac{3}{2}\right)$ & {$\left[1, \frac{9}{4}\right]$} \\
\hline $\begin{array}{c}\text { Não existe } \\
\text { indústria }\end{array}$ & $(0,0)$ & $\left(\frac{9}{4}, \infty\right)$ \\
\hline
\end{tabular}

Prova: (Vide Apêndicc)

Em suma, como a introdução dos custos enterrados, cria-sc condiçōes para que o comprometimento na quantidade a ser produ- 
zida, pcla pioneira no pcríodo derradciro, scja confiávcl; não deixando dúvidas quanto ao cumprimento da fabricação do montante da mercadoria in icialmentc cstipulado pela firma precursora. $\mathrm{O}$ que equivale a dizer, no jargão de tcoria dos jogos, que os equilíbrios encontrados em Dixit (1980) são perfeitos cm subjogos.

A conjectura de Bain, Sylos c Modigliani sobre política de preçoslimitc - ou cquivalentementc, a estratégia de impedimento à entrada - é definitivamente confirmada.

\section{A Capacidade ociosa.}

A estrutura do modelo antcrior mostra como a capacidade instalada, efetivamentc utilizada, tcm um papcl importantc na retenção à entrada. Embora, o fato da fábrica já cstar montada represente um possível inibidor de concorrência, a capacidadc ociosa, de acordo com Dixit (1980), é sinal de total desperdício, contrariando o resultado encontrado em Spence (1977).

O que se obscrva na prática são firmas com parques industriais enormes e, algumas vezes, subutilizados. Como justificar que a pequena ultilização das instalações representa um comportamento racional dos cmpresários? Os modelos discutidos até aqui, não conscguem responder a esta questão.

Nesta seção, argumenta-se - fundamentado no trabalho de Bullow, Gcanakoplos c Klcmpercr (1985b) - o valor estratégico da capacidade ociosa para uma cmpresa.

Considere que uma indústria seja formada por duas cmpresas. A firma 1 já estabclccida c a firma 2 intcrcssada em estabelecerse. De forma análoga ao modclo da sç̧ão 4, a companhia 1 decide quanto investir em instalaçõcs (custo entcrrado), $K_{1}$. Quando existe capacidade instalada, a função custo de produção é $C_{1}\left(q_{1}\right)=f+$ $K_{1}+2 q_{1}$, com custo marginal constantc c igual a 2 . Já quando as instalações estão sendo plenamentc (ou sobrc) utilizadas o custo total passa a ser $C_{1}\left(q_{1}\right)=f+3 q_{1}$, com custo marginal 3 .

A difercnça básica entrc o modclo da seção anterior c o do prescnte diz respcito a forma funcional da função de demanda pela mercadoria. Considera-sc aqui a clasticidade da demanda constante e igual a 2 , ou scja, $P(Q)=5 Q^{-1 / 2}$.

Imagine que o custo fixo de produção, $f$, é igual a $\frac{3}{20}$. Caso não haja então capacidade instalada antes do possívcl ingresso da 
empresa 2 , o equilíbrio em quantidades de Cournot é dado por:

$$
\max _{q_{1}} 5 q_{1}\left(q_{1}+q_{2}\right)^{-1 / 2}-3 q_{1}-\frac{3}{20}
$$

e

$$
\max _{q_{1}} 5 q_{2}\left(q_{1}+q_{2}\right)^{-1 / 2}-3 q_{2}-\frac{3}{20}
$$

Portanto,

$$
\begin{gathered}
\left(q_{1}^{c}, q_{2}^{c}\right)=\left(\frac{25}{32}, \frac{25}{32}\right) \\
p^{c}=4
\end{gathered}
$$

e

$$
\left(\pi_{1}^{c} \pi_{2}^{c}\right)=\frac{101}{160}
$$

Suponha, agora, que a capacidade instalada pelo 1 o empresário seja tal que torne o custo marginal de produção igual a $2 ; \operatorname{logo} K_{1} \geq$ $q_{1}$. O equilíbrio em quantidades de Cournot torna-se,

$$
\begin{aligned}
& e_{q_{1}}^{\max _{q_{1}} 5 q_{1}\left(q_{1}+q_{2}\right)^{-1 / 2}-K_{1}-2 q_{1}-\frac{3}{20}} \\
& \max _{q_{2}} 5 q_{2}\left(q_{1}+q_{2}\right)^{-1 / 2}-3 q_{2}-\frac{3}{20}
\end{aligned}
$$

que tem como condição de $1^{\underline{a}}$ ordem

$$
\begin{aligned}
& 5\left(q_{1}+q_{2}\right)^{-1 / 2}-\frac{5}{2}\left(q_{1}+q_{2}\right)^{-3 / 2} q_{1}-2=0 \\
& 5\left(q_{1}+q_{2}\right)^{-1 / 2}-\frac{5}{2}\left(q_{1}+q_{2}\right)^{-3 / 2} q_{2}-3=0
\end{aligned}
$$

Somando (5.1) e (5.2) vem:

$$
10\left(q_{1}+q_{2}\right)^{-1 / 2}-\frac{5}{2}\left(q_{1}+q_{2}\right)^{-1 / 2}-5=0
$$


Logo,

$$
q_{1}+q_{2}=\frac{9}{4}
$$

levando em (5.1) c cm (5.2) tcm-sc:

$$
\left(q_{1}^{s}, q_{2}^{s}\right)=\left(\frac{9}{5}, \frac{9}{20}\right)
$$

c, por conseguintc, o lucro do $2 \mathrm{o}$ empresário, caso entrassc, scria nulo, $\pi_{2}=0$.

Assim, o ganho do 1 o cmpresário quando cxistc um investimento pequeno em instalaçõcs $\left(K_{1}<q_{1}=\frac{25}{32}\right)$ ć $\pi_{1}=\frac{101}{160}$. E ainda, quando a capacia dade instalada na firma 1 é maior ou igual a $\frac{9}{5}$, o ingresso para o cmpresário 2 torna-sc pouco atracntc, $\pi_{2} \leq 0$.

Resta detcrminar qual scria a produção ótima para a companhia 1 , caso $K_{1}$ fossc igual a $\frac{9}{5}$. Logo,

$$
\begin{aligned}
& \max 5\left(q_{1}\right)^{-1 / 2} q_{1}-\frac{9}{5}-2 q_{1}-\frac{3}{20} \\
& q_{1}^{m}=\frac{25}{16}, \quad \text { cntão } \pi_{1}^{m}=\frac{47}{40}>\frac{101}{160} \pi_{1}^{c}
\end{aligned}
$$

Como sc pode obscrvar, o 1 o empresário vê-sc obrigado a trabalhar com uma capacidade ociosa de $\frac{9}{5}-\frac{25}{16}=\frac{19}{80}$, para impedir a entrada de novas firmas. Estc exemplo simples ilustra, de forma clara, uma situação onde instalaçõos subutilizadas têm um papel importante como barrcira à entrada. $O$ gráfico 5.1 ilustra o problcma.

$O$ intercepto da curva de reação $R_{1}($.$) c do eixo q_{1}$ representa, dada a curva de custo marginal, a produção de monopólio. Por conseguinte, quando a função de reação da firma cstabelecida tiver inclinação positiva, $R_{1}^{\prime}\left(q_{2}\right)>0$, o equilíbrio de Nash do modelo (a interseção das duas curvas de reação) sc verifica com um valor de $q_{1}$ superior a e efetivamente encontrado no caso de monopólio. Tendo em vista que o lucro do monopólio é maior do que o de $\operatorname{Cournot}^{7}$, o $1^{\text {o }}$

\footnotetext{
${ }^{7}$ Se para 1o empresário fosse mais vantajoso obter o retorno de Cournot, o proprictário da Firma estabelecida possuiria duas companhias agindo como duopolista de Cournot a invés de uma única empresa monopolista.
} 


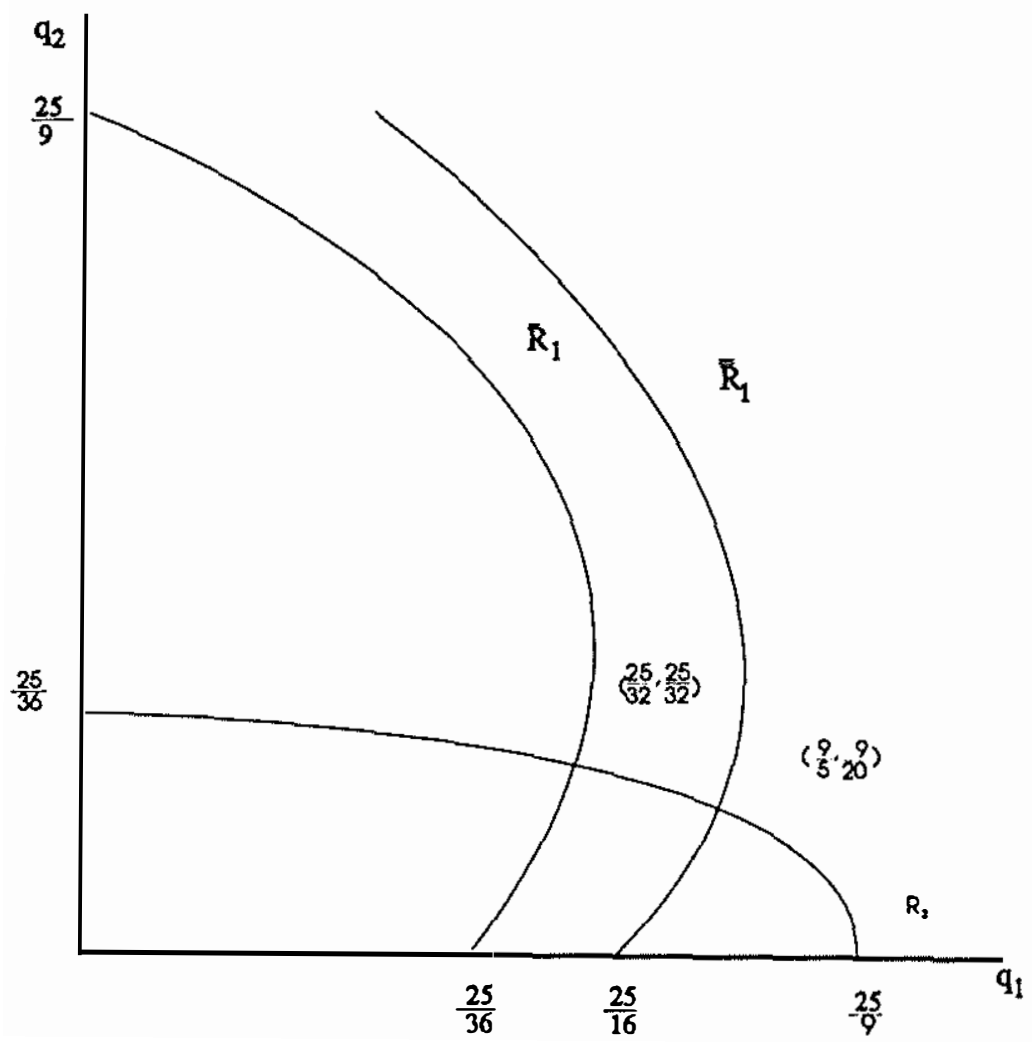

Gráfico 5.1.

As curvas são dadas por:

$$
\begin{aligned}
& \bar{R}_{1}: 5\left(q_{1}+q_{2}\right)^{-1 / 2}-\frac{5}{2}\left(q_{1}+q_{2}\right)^{-3 / 2} q_{1}-3=0 \\
& \overline{\bar{R}}_{1}: 5\left(q_{1}+q_{2}\right)^{-1 / 2}-\frac{5}{2}\left(q_{1}+q_{2}\right)^{-1 / 2} q_{1}-2=0 \\
& R_{2}: 5\left(q_{1}+q_{2}\right)^{-1 / 2}-\frac{5}{2}\left(q_{1}+q_{2}\right)^{-3 / 2} q_{1}-3=0
\end{aligned}
$$


cmpresário preferiria fabricar o montante de monopólio. No entanto, quando a empresa cstabclecida decide produzir a quantidade de monopóliø, a potencial entrante vê-sc tentada a engajar- sc na indústria. A alternativa que a pioncira teria para impedir o aliciamento da potencial ingressante seria ameaças factíveis de implementação. Um bom cxcmplo encontra-sc na cstrutura de indústria descrita acima. Imaginc que a companhia 1 invista de forma a ter $\frac{9}{5} \mathrm{~cm}$ instalações, isto levaria a não entrada da cmpresa $2\left(\pi_{2}\left(\frac{9}{5}, q_{2}\right) \leq 0\right)$ c, conscquentemente, a adoção de políticas de produção exclusiva por parte do 1o cmpresário. A capacidade ociosa de $\frac{19}{80}$, nestc contexto funciona como uma ameaça crível da pioncira, de forma que, se a frma 2 cntrar, a resposta ótima da companhia 1 scria produzir $\frac{9}{5}$, o quc, como visto, inviabilizaria o accsso da cmpresa 2.

Obscrve, com a ajuda do gráfico 5.1 , que, quando a produção da firma 2 ć pequena, isto é, quando o ponto de equilíbrio das quantidades fabricadas pelas empresas sc encontra próximo ao cixo das abcissas, um crescimento na oferta da mercadoria por parte da firma 2 leva, como resposta do 1 o cmpresário, a um aumento da produção da companhia 1. O que contrataria o resultado apresentado na seção antcrior. Em Dixit (1980), qualquer aumento na produção da firma 2 induz a uma queda na quantidade fabricada pclo $1^{\circ}$ cmpresário.

\section{Substitutos estratégicos e complementares estratégicos.}

Após a apresentação dos modclos de Dixit (1980) c Bullow, Geanakoplos e Klcmperer (1985b), uma questão deve scr melhor cntendida: o que leva a capacidade ociosa a transformar-se de puro desperdício, Dixit (1980), cm uma variável de cnorme valor cstratégico, Bullow, Geanokoplos c Klempercr (1985b)? A resposta a csta indagação csbarra na d cinição, devida a Bullow, Geanakoplos c Klemperer (1985a), de substitutos estratégicos c complementares cstratégicos.

De acordo com Bullow, Geanakoplos c Klemperer, um bem $y_{1}$ é dito substituto estratégico de $y_{2}$ se $\frac{\partial^{2} \pi_{1}}{\partial y_{1} \partial y_{2}}<0$, c ainda, $y_{1}$ ć considerado complementar estratégico de $y_{2}$ quando $\frac{\partial^{2} \pi_{1}}{\partial y_{1} \partial y_{2}}>0$. 
A terminologia substituto e complementar estratégico vem da analogia existente entre suas definições e as de bens substitutos e complementares. Como se sabe, bens substitutos (complementares) são aqueles em que o lucro da firma $i$ diminui (aumenta) com o crescimento de $y_{j}$. Por outro lado, como definido acima, os produtos substitutos (complementares) estratégicos são caracterizados pclo fato do lucro marginal - e não o lucro simples - da empresa $i$ decrescer (crescer) com a elevação do valor de $y_{j}$.

Resta mostrar a ligação existente entre a definição de Bullow, Geanakoplos e Kemplerer e a existência ou não de capacidade ociosa.

Primeiramente, observa-se que, o equilíbrio de Nash, $\left(q_{1}^{*}, q_{2}^{*}\right)$, satisfaz a condição de maximização de lucro,

$$
\frac{\partial \pi_{1}}{\partial q_{1}}\left(q_{1}^{*}, q_{2}^{*}\right) \quad=0
$$

e

$$
\frac{\partial^{2} \pi_{1}}{\partial q_{1}^{2}}\left(q_{1}^{*}, q_{2}^{*}\right) \quad<0^{8}
$$

Tendo em vista que, a estratégia ótima para 10 empresário é $R_{1}\left(q_{2}\right)$, a condição de $1^{\underline{a}}$ ordem do problema de otimização, também pode ser escrita da forma:

$$
\begin{gathered}
\frac{\partial \pi_{1}\left(R_{1}\left(q_{2}\right), q_{2}\right)}{\partial q_{1}}=0 \\
\frac{\partial^{2} \pi_{1}\left(R_{1}\left(q_{2}\right), q_{2}\right)}{\partial q_{1}^{2}}<0^{9}
\end{gathered}
$$

Diferenciando a equação (6.1), obtém-se:

$$
R_{1}^{\prime}\left(q_{2}\right)=-\frac{\partial^{2} \pi_{1}\left(R_{1}\left(q_{2}\right), q_{2}\right)}{\partial q_{1} \partial q_{2}}\left[\frac{\partial^{2} \pi_{1}\left(R_{1}\left(q_{2}\right), q_{2}\right)}{\partial q_{1}^{2}}\right]^{-1}
$$

De (6.2) e (6.3), tem-se:

${ }^{8}$ Considere que a função lucro é estritamente côncava em sua variável de decisão, $q_{1}$

${ }^{9} q_{1}=R_{1}\left(q_{2}\right)$ é único da hipótese de estrita concavidade. 
$\operatorname{Sinal}\left[R_{1}^{\prime}\left(q_{2}\right)\right]=\operatorname{sinal}\left[\frac{\partial^{2} \pi_{1}}{\partial q_{1} \partial q_{2}}\left(R_{1}\left(q_{2}\right), q_{1}\right)\right]$

Portanto, quando o bem é substituto (complementar) estratégico, a curva de reação tem inclinação negativa (positiva).

Para finalizar, recorre-se aos modelos apresentados nas secões 4 e 5. No modo de ver de Dixit (1980), as curvas de reação são negativamente inclinidas, fazendo com que as instalaçõcs subutilizadas sejam sinônimo de desperdício. Por outro lado, Bullow, Geanakoplos e Klemperer, conhecendo as limitações inerentes à hipótese de bens substitutos estratégicos adotada por Dixit, constróem um contraexemplo - com complementaridade estratégica das mercadorias no equilíbrio - onde a ociosidade da capacidade é ótimo estratagema como barreira à entrada.

\section{Conclusão.}

Duran te todo o trabalho, foram discutidos modelos em que a tecnologia de produção era de livre acesso e de domínio público. Com isso, procurou-se destacar as vantagens inerentes ao fato de uma firma ser a precursora em uma indústria.

Com a ajuda de um modelo de expectativas racionais simples de dois períodos, alguns importantes resultados foram encontrados. Vale mencionar os principais:

(i) A introdução do custo entcrrado, através de investimentos em instalações pela firma pioneira, garantc à empresa precursora a possibilidade de trabalhar com lucro positivo.

(ii) A conjectura de Bain, Sylos-Labini e Modigliani é validada. Em algumas ocasiões, a política de preços-limite é a melhor estratégia de um monopolista.

(iii) Dependendo da função de custos da indústria, a capacidade ociosa pode representar total desperdício de capital como, por outro lado, pode ser uma variável de grande valor estratégico.

Em suma, o simples fato de um empresário ter sido o primciro a operar $\mathbf{n a}$ indústria garante-lhe um lucro de longo-prazo acima do de competição.

\section{Referências}

Bain, J. Barriers to New Competition, Cambridge, Mass. Harvard 
University Press. 1950.

Baumol, W., Panzar, J. c Willig, R. Contestable Markets and the Theory of Industry Structure. New York, Hancourt Brace Jovanovich, 1982.

Bullow, J., Geanokoplos, J. c Klemperer, P. Multimarket Oligopoly: Strategic Substitutes and Complements. Journal of Political Economy, 93: 488-511, 1985a.

Bullow, J., Gencanokoplos, J. c Klcmperer, P. Holding Idlc Capacity to Deter Entry. Economic Journal, 95: 178-182, 1985b.

Dixit, A. A Model of Duopoly Suggesting a Theory of Entry Barricrs. Bell Journal of Economics, 10: 20-32, 1979.

Dixit, A. The Role of Investment in Entry Deterrence. Economic Journal, 90: 95-106, 1980.

Gilbcrt, R. Mobility Barriers and the Value of Incumbency, Handbook of Industrial Organization, Vol. 1, cap. 8, ed. R. Schmalensee e $R$. Willig. Amsterdam, North-Holland, 1989.

Modigliani, F. New Developments on the Oligopoly Front. Journal of Political Economy, 66: 215-232, 1958.

Shapiro, C. Theories of Oligopoly Behavior, Handbook of Industrial Organization, vol. 1, cap. 6, ed. R. Schmalensee e R. Willig. Amstcrdam, North-Holland, 1989.

Spence, A.M. Entry Capacity, Investment and Oligopolistic Pricing. Bell Journal of Economics, 8:534-544, 1977.

Stigler, G. The Organization of Industry, Homewood, Ill. Irwin. 1968. Sylos-Labini, P. Oligopoly and Technical Progress, Cambridge, Mass.: Harvard University Press. 1962.

Tirole, J. The Theory of Industrial Organization, Cambridge, Mass.: The MIT Press. 1989. 


\section{APÊNDICE}

\section{Seção 2 .}

Prova da Proposição 2.1: A acomodação à entrada ocorrc quando é mais rentável para a firma 1 permitir o ingresso da companhia 2.

Sabc-sc que no cquilíbrio de Stackelberg, a cmpresa 2 maximiza scu lucro dada a decisão de produção da companhia 1 ,

$$
\max _{q_{2}} q_{2}\left(3-q_{1}-q_{2}\right)-f
$$

da condição de $1^{\underline{a}}$ ordem, vem:

$$
q_{2}=\frac{3-q_{1}}{2}
$$

Enquanto que a firma 1 otimiza scu retorno sujcito a cstratégia de produção adotada pcla cmpresa 2 ,

$$
\max _{q_{1}}\left(3-q_{1}-q_{2}\right) q_{2}-f=\max _{q_{1}}\left[1-q_{1}-\frac{1-q_{1}}{2}\right] q_{1}-f
$$

Resolvendo o problema de otimização, tem-sc:

$$
\left(q_{1}^{s a}, q_{2}^{s a}\right)=\left(\frac{3}{2}, \frac{3}{4}\right)
$$

Resta saber para que valores de $f$ o cquilíbrio $\left(\frac{3}{2}, \frac{3}{4}\right)$ prevalece. Quando $\left(q_{1}, q_{2}\right)$ é igual a $\left(\frac{3}{2}, \frac{3}{4}\right)$, o ganho da cmpresa 1 é $\pi_{1}\left(\frac{3}{2}, \frac{3}{4}\right)=\frac{9}{8}-f$.

Mas, devido ao custo fixo, existem quantidades de $q_{1}$ que demoveriam a cmpresa 2 da idéia de engajamento na indústria. Entretanto, cstc valor de $q_{1}$, mesmo com $q_{2}$ sendo nulo, pode não ser atrativo para o 1 o cmpresário. Desta feita, deve-sc calcular o valor máximo de $q_{1}$ que induziria a companhia 1 a climinar a possibilidade de cntrada. Quando $q_{2}$ é nulo, o valor de $q_{1}$ que satisfaz à $\pi_{1}\left(q_{1}, 0\right)=\frac{9}{8}-f$ é $q_{1}^{\prime}=\frac{3}{4}[2+\sqrt{2}]$. A firma 1 só se dispõc-sc a barrar à entrada de novas 
empresas se, para fazĉ-lo, não for necessário produzir uma quantidade $q_{1}$ acima de $q_{1}^{\prime}$, já que, $\pi_{1}\left(q_{1}, 0\right)<\pi_{1}\left(\frac{3}{2}, \frac{3}{4}\right)$ para $q_{1}>q_{1}^{\prime}=\frac{3}{4}[2+\sqrt{2}]$.

Como se pode observar, a realização de $f$ a partir da qual a firma 2 não tem interesse de entrar e a empresa 1 prefere impedir à entrada é tal que:

$$
\pi_{2}\left(\frac{3}{4}[2+\sqrt{2}], 0\right)=0
$$

ou seja,

$$
f=\frac{9}{64}[2-\sqrt{2}]^{2}
$$

Portanto, para $f<\frac{9}{64}[2-\sqrt{2}]^{2}$ a firma estabclecida prefere accitar uma nova companhia agindo na indústria, c a produção de equilíbrio no setor é $\left(q_{1}^{s a}, q_{2}^{s a}\right)=\left(\frac{3}{2}, \frac{3}{4}\right)$.

Prova da Proposição 2.2: $\quad$ O bloqueio à entrada é observado quando a firma já instalada pode produzir a quantidade de monopólio sem estimular entrada.

A produção de monopólio é determinada através da maximização de lucro da companhia 1.

$$
\max _{q_{1}}\left[3-q_{1}\right] q_{1}-f
$$

o que acarreta $q_{1}=\frac{3}{2} \cdot 10$

Para que a melhor resposta da potencial entrante scja o não ingresso, o lucro da mesma, no caso de engajamento na indústria, deve ser negativo. Dessa forma, verifica-se que para qualquer valor $\int$ maior que, $\frac{9}{16}$, a função lucro $\pi_{1}\left(\frac{3}{2}, q_{2}\right)$ é menor que zero.

Assim, se $f>\frac{9}{16}$, a firma 2 entra no mercado, c a pioneira pode cotar o preço de monopólio sem ser importunada. Observe que, para $f>\frac{9}{4}$ o retorno da empresa 1 torna-se negativo. Como se vê, o

${ }^{10}$ A quantidade produzida pela firma 1 no caso de monopólio é a mesma da produzida no caso de acomodação à entrada, devido à particularidade das funções consideradas. 
bloqucio à entrada, $\left(q_{1}^{s b}, q_{2}^{s b}\right)=\left(\frac{3}{2}, 0\right)$, ocorrcrá quando $f \in\left(\frac{9}{16}, \frac{9}{4}\right)$

Prova da Proposição 2.3: O impedimento à entrada resulta de uma política de produção, por parte da empresa instalada, que torna inviável o engajamento de uma nova firma no setor.

Isto posto, obscrva-sc, da proposição 2.1 , que $\pi_{1}\left(q_{1}, 0\right) \geq \pi_{1}\left(\frac{3}{2}, \frac{3}{4}\right)$ para $q_{1} \in\left[\frac{3}{2}, \frac{3}{4}[2+\sqrt{2}]\right]$ c que a função $n_{1}\left(q_{1}, 0\right)$ é estritamente dccrescente no primciro argumento para $q_{1} \in\left(\frac{3}{2}, 3\right)$. Sabc-sc ainda, das proposiçōes anteriores, que os valores de custo fixo que criam condiçōes para impedir à entrada são $f \in\left[\frac{9}{64}[2-\sqrt{2}]^{2}, \frac{9}{16}\right]$. Dessa forma, a firma 1 escolherá um valor $\max _{q_{2}}\left(3-q_{1}-q_{2}\right) q_{2}-\int$ igual a zcro. Assim, a função de reação ótima da companhia 2 ć $R_{2}\left(q_{1}\right)=\frac{3-q_{1}}{2}$. E o 1o empresário produzirá uma quantidade de $q_{1}$, de forma a que $\left[3-q_{1}-\left[\frac{3-q_{1}}{2}\right]\right] \frac{3-q_{1}}{2}=f$, ou scja, $q_{1}^{s i}=3-2 \sqrt{f}$.

Desta feita, a estratégia de impedimento à entrada ć utilizada pela pioncira quando $f \in\left[\frac{9}{64}[2-\sqrt{2}]^{2}, \frac{9}{16}\right]$, c o equilíbrio ocorre no ponto $\left(q_{1}^{s i}, q_{2}^{s i}\right)=(3-2 \sqrt{J}, 0)$.

\section{Seção 4.}

Prova da Proposição 4.1: Para um melhor entendimento da determinação do(s) equilíbrio(s), analisam-sc trĉs situaçōes:

(i) $\pi_{2}(1,1)<0, \quad f>1$

Para os valores do custo fixo maiores do que 1 os equilíbrios são análogos aos ilustrados pclo gráfico 2.1. O pioncirismo não propicia à firma 1 nenhuma vantagem sobre a empresa 2 , como discutido pela equação 2.1 .

Logo,

$$
\left(q_{1}, q_{2}\right)=\left\{\begin{array}{c}
\left(\frac{3}{2}, 0\right) \text { ou }\left(0, \frac{3}{2}\right), \text { se } 1<f \leq \frac{9}{4} \\
(0,0), \quad \text { se } \quad f>\frac{9}{4}
\end{array}\right.
$$


(ii) $\pi_{2}\left(\frac{5}{3}, \frac{2}{3}\right)>0, f<\frac{4}{9}$

Neste caso, as duas empresas fabricam o bem e o equilíbrio é o de Stackelberg, onde a companhia 1 é a líder, como discutido anteriormente (ver gráfico 4.5).

Dessa maneira,

$$
\left(q_{1}, q_{2}\right)=\left(\frac{3}{2}, \frac{3}{4}\right), \quad \text { para } \quad f<\frac{4}{9}
$$

(iii) $\pi_{2}(1,1)>0>\pi_{2}\left(\frac{5}{3}, \frac{2}{3}\right), \quad \frac{4}{9}<f<1$.

Imagine que $f$ seja igual a $\frac{4}{9}$ c a empresa 1 produza $\frac{5}{3}$, então a firma 2 ficaria indiferente entre nada produzir e fabricar sua quantidade ótima de entrada, $\frac{2}{3}$,

$$
\pi_{2}\left(\frac{5}{3}, \frac{2}{3}\right)=\pi_{3}\left(\frac{5}{3}, 0\right), \quad \text { sc } \quad f=\frac{4}{9} .
$$

O ganho da companhia 1 , no caso do par de equilíbrio $\left(q_{1}, q_{2}\right)=$ $\left(\frac{5}{3}, 0\right)$, é $\pi_{1}\left(\frac{5}{3}, 0\right)=\frac{16}{3}$ para $f=\frac{4}{9}$.

Não obstante, se a pioncira fabricar a quantidade de Stackelberg, $q_{1}=\frac{3}{2}$, a entrante responde com $q_{2}=\frac{3}{4}$. Como $\pi_{1}\left(\frac{5}{3}, 0\right)=\frac{16}{9}$ é maior que $\pi_{1}\left(\frac{3}{2}, \frac{3}{4}\right)=\frac{49}{72}$ a companhia 1 prefere impedir à entrada com $q_{1}$ igual a $\frac{5}{3}$.

Além do mais, como $\pi_{1}\left(q_{1}, 0\right)$ com $q_{1} \in\left(\frac{3}{2}, \frac{5}{3}\right)$ é decrescente no primeiro argumento da função, o 1을 empresário decide produzir ao nível de $q_{1}$ mínimo, tal que não permita a entrada da concorrente, quando $q_{1} \in\left(\frac{3}{2}, \frac{5}{3}\right)$. Assim, os valores de $q_{1}$ são tais que tornam o ganho da companhia 2 nulo,

$$
\begin{aligned}
& \frac{3-q_{1}}{2}\left(3-q_{1}-\frac{3-q_{1}}{2}\right)-f=0 \\
& \Rightarrow q_{1}=3-2 \sqrt{f}, \quad \text { para } \quad f \in\left(\frac{4}{9}, \frac{9}{16}\right)
\end{aligned}
$$


Quando $f$ é maior que $\frac{9}{16}$, a pioneira bloqueia à entrada produzindo o montante de monopólio.

Logo,

$$
\begin{aligned}
& \left(q_{1}, q_{2}\right)=(3-2 \sqrt{f}, 0), \quad \text { para } \quad f \in\left[\frac{4}{9}, \frac{9}{16}\right] \\
& \left(q_{1}, q_{2}\right)=\left(\frac{3}{2}, 0\right), \quad \text { para } \quad f \in\left(\frac{9}{16}, 1\right)
\end{aligned}
$$

Assim, tem-se bloqueio à entrada $\left(q_{1}, q_{2}\right)=\left(\frac{3}{4}, 0\right), \quad f \in\left(\frac{9}{16}, 1\right)$, impedimento à entrada $\left(q_{1}, q_{2}\right)=(3-2 \sqrt{f}, 0) \quad f \in\left[\frac{4}{9}, \frac{9}{16}\right]$ e acomodação à entrada $\left(q_{1}, q_{2}\right)=\left(\frac{3}{2}, \frac{3}{4}\right), f \in$ $\left[0, \frac{4}{9}\right)$. 
130 